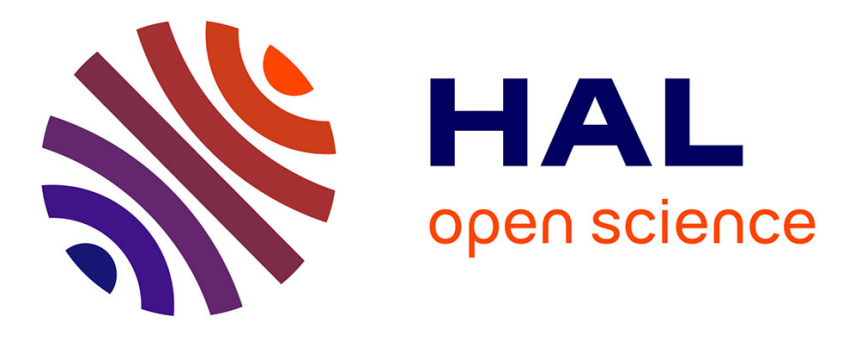

\title{
Confinement of the Pentanitrogen Cation Inside Carbon Nanotubes
}

Stefano Battaglia, Stefano Evangelisti, Thierry Leininger, Noelia Faginas Lago

\section{To cite this version:}

Stefano Battaglia, Stefano Evangelisti, Thierry Leininger, Noelia Faginas Lago. Confinement of the Pentanitrogen Cation Inside Carbon Nanotubes. Osvaldo Gervasi, Beniamino Murgante, Sanjay Misra, Elena Stankova, Carmelo M. Torre, Ana Maria A.C. Rocha, David Taniar, Bernady O. Apduhan, Eufemia Tarantino, Yeonseung Ryu. Computational Science and Its Applications - ICCSA 2018., 10964, Springer, pp.579-592, 2018, Lecture Notes in Computer Science, 978-3-319-95173-7. 10.1007/978-3-319-95174-4_45. hal-01876551

\section{HAL Id: hal-01876551 https://hal.science/hal-01876551}

Submitted on 5 Oct 2018

HAL is a multi-disciplinary open access archive for the deposit and dissemination of scientific research documents, whether they are published or not. The documents may come from teaching and research institutions in France or abroad, or from public or private research centers.
L'archive ouverte pluridisciplinaire HAL, est destinée au dépôt et à la diffusion de documents scientifiques de niveau recherche, publiés ou non, émanant des établissements d'enseignement et de recherche français ou étrangers, des laboratoires publics ou privés. 


\section{ACCEPTED MANUSCRIPT}

The final publication is available at link.springer.com at the following link:

https://link.springer.com/chapter/10.1007\%2F978-3-319-95174-4_45

DOI: https://doi.org/10.1007/978-3-319-95174-4 


\title{
Confinement of the Pentanitrogen Cation Inside Carbon Nanotubes
}

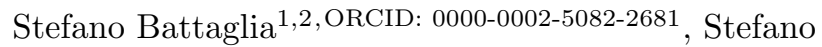 \\ Evangelisti ${ }^{1}$, ORCID: 0000-0001-8782-443X , Thierry \\ Leininger 1,ORCID: 0000-0002-7373-0966, and Noelia \\ Faginas-Lago 2, ORCID: 0000-0002-4056-3364 \\ 1 Laboratoire de Chimie et Physique Quantiques, IRSAMC, Université de Toulouse \\ et CNRS, 118 Route de Narbonne, F-31062 Toulouse Cedex, France \\ stefano@irsamc.ups-tlse.fr Thierry.Leininger@irsamc.ups-tlse.fr \\ 2 Dipartimento di Chimica, Biologia e Biotecnologie, Università degli Studi di \\ Perugia, Vie Else di Sotto 8, I-06123 Perugia, Italy \\ noelia.faginaslago@unipg. it
}

\begin{abstract}
In recent years, the field of polynitrogen chemistry has seen a sparking activity, with new outstanding theoretical and experimental results. Polynitrogen clusters are excellent candidates for high-energy density materials, but their intrinsic instability poses great challenges for the synthesis and the subsequent storage. In this work, we explore by means of quantum chemical calculations the confinement of the pentanitrogen cation, $\mathrm{N}_{5}^{+}$, inside carbon nanotubes of different diameters. The interaction of the two fragments is such that a charge transfer from the nanotube to the nitrogen cation occurs and leads to the subsequent decomposition of $\mathrm{N}_{5}^{+}$, thus resulting in an overall unstable system. Nonetheless, preliminary results on the confinement of the neutral $\mathrm{N}_{8}$ chain (as the product of an $\mathrm{N}_{5}^{+}+\mathrm{N}_{3}^{-}$addition) are presented, where it is shown that the encapsulation decreases the overall energy of the complex system. Two stable $\mathrm{N}_{8}$ isomers are discussed and a first investigation on possible decomposition pathways is carried out.
\end{abstract}

Keywords: Carbon Nanotubes, HEDM, Molecular Confinement, Polynitrogen, Pentanitrogen Cation

\section{Introduction}

Probably the most peculiar property of nitrogen is the incredible energy difference between single, double and triple bond[1]. Three times the energy of a single bond corresponds to less than half of the energy of a triple bond; thus it should not come as a surprise that nitrogen exists naturally only in its molecular form. Single- and double-bonded polynitrogen (PN) clusters contain a huge amount of energy and have been proposed as possible high-energy density materials (HEDM) $[1,2]$. Additionally to their potential to store energy, they have an innocuous effect on the environment, since decomposition of pure nitrogen 
clusters usually leads to the release of $\mathrm{N}_{2}$ only.

The $\mathrm{N}_{3}^{-}$azide anion was the first pure nitrogen molecule experimentally synthesized in a lab[3] and after this achievement in 1890, it took more than a century before the pentanitrogen cation $\mathrm{N}_{5}^{+}$was successfully isolated in 1999 by Christe and coworkers[4]. Since then, an incredible amount of work has been done trying to predict new stable species entirely composed by nitrogen as HEDM candidates.

Many theoretical and partly experimental investigations focused on possible pure nitrogen salts composed by the ions $\mathrm{N}_{3}^{-}, \mathrm{N}_{5}^{+}$and $\mathrm{N}_{5}^{-}$[5-10]. Other groups focused more on the possibility to either synthesize new PN molecular crystals or identify novel molecular nitrogen phases[11,12], both of which are often attainable only under extreme conditions. Most notably, the cubic gauche polymeric nitrogen form was successfully synthesized a few years ago under very high temperature and pressure[13].

In recent years, different PN clusters and molecular crystals were theoretically predicted and some were experimentally obtained [14-20]. In 2017, two main achievements renovated once again the interest in the field, namely the isolation and characterization of cyclo- $\mathrm{N}_{5}^{-}$pentazolate[21] and the synthesis of the cubic gauche form of nitrogen under near-ambient conditions[22].

Despite the recent successes, other ways to stabilize (and hopefully store) singleand double-bonded PN clusters were proposed too, in particular molecular confinement. For the latter approach, carbon nanomaterials such as fullerenes, carbon nanotubes (CNTs) and graphene layers appear as ideal candidates. By spatially confining PN clusters inside the cavity of such materials, thanks to less geometrical freedom as well as non-bonded interactions with the hosting system, the guest fragments may be favorably stabilized and stored. First investigations in this direction have proposed the encapsulation of nitrogen chains inside carbon nanotubes and have theoretically predicted, as well as later experimentally observed, the feasibility of this approach[22-27]. Besides carbon nanotubes, other types of carbon nanostructures as well as other nanomaterials have been proposed as valid alternatives[28-32].

In this work, we extend our previous contribution[33] in which we studied the confinement inside carbon nanotubes of the simplest PN cluster, the azide anion, by investigating the second-longest experimentally accessible PN compound, the pentanitrogen cation. Furthermore, we discuss preliminary results on a more challenging system: an encapsulated molecular $\mathrm{N}_{8}$ chain confined inside a $(5,5)$ CNT.

The article is organized as follows: the next Section lists the computational details of the calculations carried out in this study. In the Results Section, we firstly present and discuss the main findings regarding the pentanitrogen cation, and secondly, we include some preliminary results regarding the encapsulation of $\mathrm{N}_{8}$. Finally, in the Conclusions Section, we highlight the main achievements of this work and briefly outline the aim of this research. 


\section{Computational Details}

Carbon nanotubes used in this work were treated as finite-size systems, with addition of hydrogen atoms at the two ends in order to saturate the dangling carbon atoms. Two classes were considered, namely zigzag nanotubes with helical indices $(n, 0)$ and armchair nanotubes with helical indices $(m, m)$. In the case of $(n, 0)$ CNTs, $n$ was chosen equal to 8,10 or 12 , while for armchair nanotubes, the values of $m$ considered were 4,5 or 6 . This choice of indices provided CNTs with a diameter in the range comprised between $6.26 \AA$ and $9.40 \AA$. The length of the nanotubes was $\approx 13.57 \AA$ for zigzag and $\approx 15.43 \AA$ for armchair CNTs, respectively.

The fragment geometries used in the unrelaxed interaction energies calculations were optimized using density functional theory (DFT), employing the Becke exchange energy functional $[34,35]$ and the Lee-Yang-Parr correlation energy functional[36] (B3LYP). The CNTs were optimized for the lowest electronic state at this level of theory, namely the triplet and singlet state for zigzag and armchair nanotubes, respectively. The polynitrogen molecules were minimized for the closed-shell singlet state.

On the other hand, calculations involving $\mathrm{N}_{8}$ as well as the relaxation of any complex systems, were carried out using the APFD density functional[37], which will be discussed directly in the Results section.

In all calculations, the double- $\zeta$ 6-31G basis set[38] was used for hydrogen and carbon, while diffuse and polarization functions were added for nitrogen (6$\left.31+\mathrm{G}^{*}\right)$. Interaction energies presented in this work were corrected for the basis set superposition error using the counterpoise correction scheme introduced by Boys and Bernardi[39]. The single point energies involving the pentanitrogen cation were calculated either by second-order Møller-Plesset perturbation theory (MP2) or second-order $n$-electron valence perturbation theory (NEVPT2)[4042], while the preliminary study on $\mathrm{N}_{8}$ was carried out entirely using DFT. The need for multireference perturbation theory (NEVPT2) resulted necessary for zigzag nanotubes, which similarly to other low-dimensional zigzag hydrocarbons have a ground state of open-shell character. Reference wavefunctions for calculating NEVPT2 energies were obtained using the complete active space self-consistent field (CASSCF) method[43]. The active space used was that of 10 electrons in 10 molecular orbitals, all belonging to the carbon nanotube.

All calculations in this contribution were carried out using either the 2015.1 version of the MOLPRO program package[44, 45] or the Gaussian09 software, version D01[46]. Natural population analyses (NPA)[47] were performed using the NBO program version 3.1[48] bundled in the Gaussian09 software, while all figures including molecular structures were generated using the Avogadro program[49].

\section{Results}

The first approach of this study consisted in the calculation of unrelaxed interaction energies between the $\mathrm{N}_{5}^{+}$cation confined inside different carbon nanotubes, 
where the $\mathrm{N}_{5}^{+}$was placed in the middle of the nanotubes, from both the edges and the wall. The computed values are plotted in Figure 1 as a function of the CNTs diameter. For all nanotubes except the smallest $(4,4)$ one, the energy is

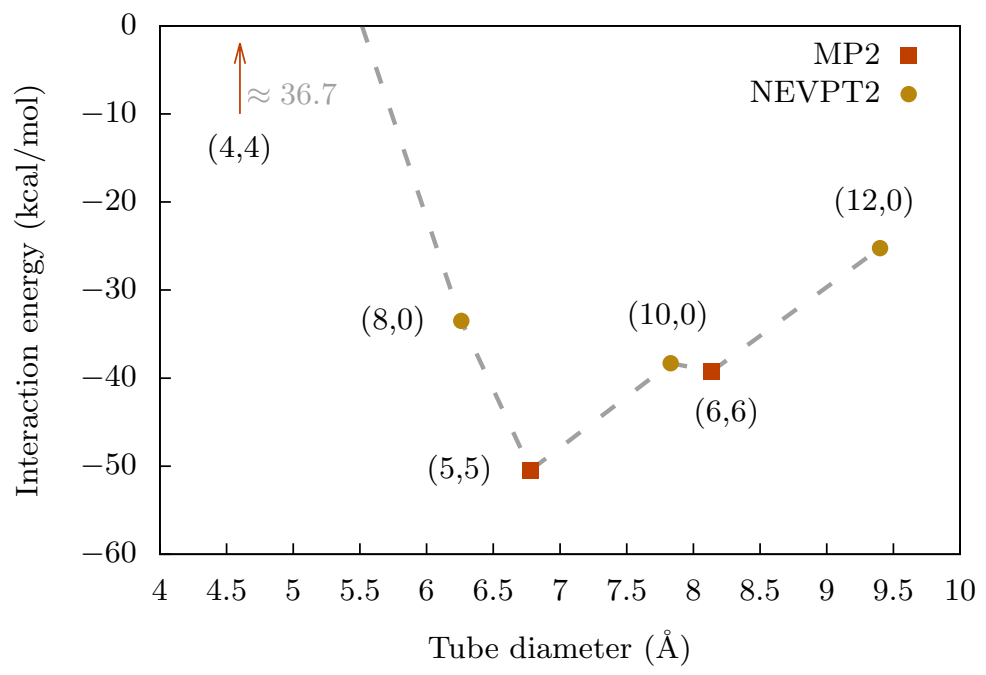

Fig. 1. Unrelaxed interaction energies as a function of the CNT diameter

negative, thus suggesting a favorable interaction between the two fragments. The magnitude of the interaction appears to be independent from the helicity of the CNT and to relate only to the diameter of the latter. This is due to the distance of the confined species from the nanotube wall. The small bump observed for nanotubes $(10,0)$ and $(6,6)$ is most likely due to the different methodologies applied to obtain the energies.

In the case of armchair nanotubes, the ground state of the complex system is a closed-shell singlet state, thus allowing the account of relaxation effects by performing a geometry optimization using restricted DFT. This is not the case for zigzag nanotubes, where a multireference approach is strictly required, since broken-symmetry DFT fails to accurately describe the electronic structure of the ground state. Luckily, the most favorable interaction is observed for the $(5,5) \mathrm{CNT}$, with a value of $-50.44 \mathrm{kcal} / \mathrm{mol}$. Thus, we have relaxed the $\mathrm{N}_{5}^{+} @ \mathrm{CNT}(5,5)$ system using DFT in combination with the APFD exchange and correlation functional[37]. One of the shortcomings of DFT is the inability of accurately describing long-range dispersion effects by means of standard GGA or hybrid density functionals. In recent years, different schemes to solve these problems have been devised and the APFD functional was designed with this goal in mind. In particular, dispersion effects are accounted for from an empirical dispersion scheme based on spherical atom dispersion terms. In our previous 
study, we have observed a good performance of the APFD functional, especially the ability to accurately reproduce MP2 interaction energies[33].

Surprisingly, the relaxation process led to the breaking of the $\mathrm{N}_{5}^{+}$compound confined in the nanotube. The decomposition process happens barrierless, as can be seen from Figure 2, where the relative energies and a few intermediate geometries of the PN species are depicted. In order to ensure the bond breaking was not an

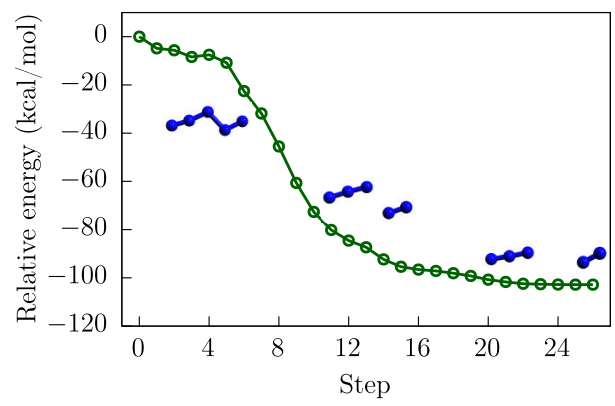

Fig. 2. Relative energies w.r.t. step zero during the relaxation process. Geometries at steps 7, 11 and 26 are depicted along the curve without the surrounding nanotube for better representation.

artifact due to the choice of functional, the optimization was repeated with the B3LYP density functional with inclusion of the D3 dispersion scheme[50]. Also in this case however, the result was the same with the breaking of the confined guest system happening barrierless.

Additional to the system $\mathrm{N}_{5}^{+} @ \mathrm{CNT}(5,5)$, the relaxation using the APFD functional was performed on the smaller $(4,4)$ and larger $(6,6)$ CNTs, respectively. In both cases, the confined cation breaks again after a few optimization cycles, leading to final conformations exemplified by Figure 3 for one of the two nanotubes.

In order to investigate the nature of the bond breaking, we performed a series

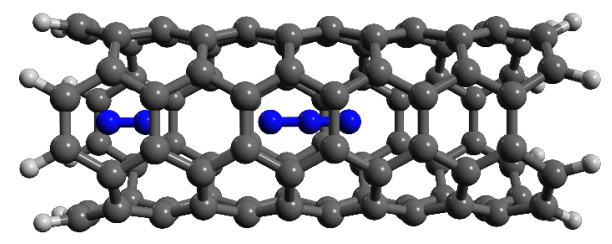

Fig. 3. Final structure of $\mathrm{N}_{5}^{+} @ \mathrm{CNT}(4,4)$

of natural population analyses of the APFD electron density. The analysis of the $\mathrm{N}_{5}^{+}$cation in gas phase assigned the partial atomic charges according to 
Figure 4 . The molecule is symmetric and belongs to the $\mathrm{C}_{2 v}$ molecular point

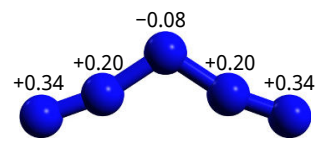

Fig. 4. Partial atomic charges of the $\mathrm{N}_{5}^{+}$cation in gas phase

group and thus its charge distribution is symmetric with respect to the central nitrogen atom. By repeating the NPA on the nitrogen cation confined inside the $(5,5)$ CNT before the geometry relaxation, a significantly different charge distribution appears, as can been seen in Figure 5. Note how only the partial

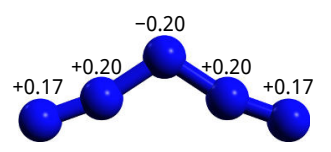

Fig. 5. Partial atomic charges of the $\mathrm{N}_{5}^{+}$cation confined inside the cavity of a $(5,5)$ CNT

charges of the two external atoms as well as the central one are affected, because of their vicinity to the nanotube wall. The total sum of the partial charges on the $\mathrm{N}_{5}^{+}$is 0.57 , implying a (partial) charge transfer from the nanotube to the cation.

A third and last NPA on the fully relaxed geometry revealed that after bond breaking, an even larger charge transfer occurred and a total of two electrons were given by the nanotube to the nitrogen species. Figure 6 shows the partial charge distribution of the two (nitrogen) fragments, where the total charge on the $\mathrm{N}_{3}$ fragment is virtually minus one, while that of $\mathrm{N}_{2}$ is approximately zero. The double electron transfer is most likely the trigger of the dissociation hap-

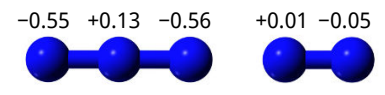

Fig. 6. Partial atomic charges of the decomposed fragments after relaxation inside the cavity of a $(5,5)$ CNT

pening inside the cavity.

It was shown in a previous work[10] that the $\mathrm{N}_{5}^{\bullet}$ radical species dissociates barrierless into the products $\mathrm{N}_{3}^{\bullet}$ radical and neutral $\mathrm{N}_{2}$. In order to be sure that this decomposition is described correctly by our methodological approach, we 
successfully reproduced the dissociation using the APFD functional.

For the first electron transfer from the CNT to the $\mathrm{N}_{5}^{+}$to occur, the electron affinity (EA) of the pentanitrogen cation has to be larger than the ionization potential (IP) of the carbon nanotube. The IP of a hydrogen-terminated $(5,5)$ CNT was studied by Buonocore et al. [51] and estimated to be between 4.2 and $5.2 \mathrm{eV}$ depending on the approach used to compute it. The (vertical) electron affinity of $\mathrm{N}_{5}^{+}$on the other hand, is obtained in this work according to the formula $\mathrm{EA}=E(N)-E(N+1)$, where $N$ stands for the number of electrons and $E(N)$ and $E(N+1)$ are total electronic energies computed at the geometry of the system with $N$ electrons. The value calculated for $\mathrm{N}_{5}^{+}$using the APFD functional is $6.37 \mathrm{eV}$, thus resulting in an estimated difference between the EA of $\mathrm{N}_{5}^{+}$and the IP of $\operatorname{CNT}(5,5)$ in the range $\approx 2.17-3.17 \mathrm{eV}$. Although this is just a qualitative result, it proves how it is energetically favorable for the nanotube to transfer an electron to the cation, triggering the decomposition reaction. Therefore, we argue that there would not even be the necessity for the second electron transfer in order for the bond breaking to occur. Note that the charge transfer could be in principle influenced by the finite-size model of the CNT used in this work, since the IP depends on the length of the system. However, in Ref. [51] it is shown that the CNT IP decreases as a function of the length of the tube, thus in the limit of an infinite nanotube, the transfer would be even more favored by the smaller IP. Consequently, we argue that by modeling the CNT using periodic boundary conditions, the first electron transfer would be observed as well, initiating the decomposition of $\mathrm{N}_{5}^{+}$. Finally, to understand the second charge transfer process, an argument based on EA and IP is certainly harder to make as it is not known a priori at which moment of the reaction the transfer occurs and it would require a more detailed study which goes beyond the scope of this investigation.

A possible way to avoid the electron transfer process and the subsequent decomposition, is the encapsulation into the cavity of a counterion together with $\mathrm{N}_{5}^{+}$, such that the interaction between the two confined species is stronger than that of the cation with the CNT. A possible candidate is the azide anion, which is proven to be favorably confined inside carbon nanotubes[33]. Moreover, the reaction $\mathrm{N}_{5}^{+}+\mathrm{N}_{3}^{-} \rightarrow \mathrm{N}_{8}$ was extensively studied by Fau and Bartlett showing all possible reaction patways in gas phase[7].

In that work, the authors have come to the conclusion that linear isomers of molecular $\mathrm{N}_{8}$ are not stable at ambient conditions due to low activation barriers leading to dissociation. In particular they suggested that the lattice energy of a crystal made by $\mathrm{N}_{5}^{+}$and $\mathrm{N}_{3}^{-}$ion pairs could increase sufficiently the barriers and make $\mathrm{N}_{8}$ stable. In 2014, a crystal structure for the $\mathrm{N}_{8}$ molecule was theoretically predicted by DFT calculations to be stable at ambient conditions, although not composed by the ion pair, but instead by a combination of the linear isomers[14]. Here, we present some preliminary results on the confinement of two $\mathrm{N}_{8}$ linear isomers inside the cavity of a $(5,5)$ carbon nanotube. From the different stable isomers identified in Ref. [7], we consider in the following only the EEE and 
EZE conformers (adopting the same nomenclature of Ref. [7]) represented in Figure 7, as they appear particularly suited for confinement inside CNTs due to their linear structure. For both isomers, there are two possible decomposi-
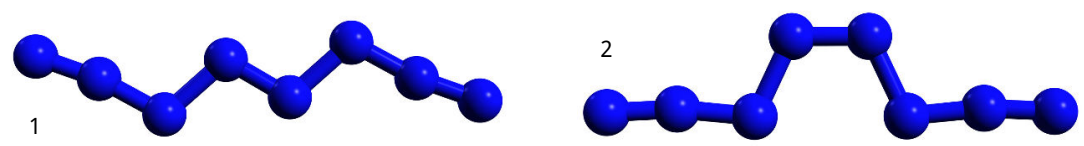

Fig. 7. Two stable $\mathrm{N}_{8}$ isomers, (1) the EEE conformation and (2) the EZE conformation

tion pathways: in one case a terminal $\mathrm{N}_{2}$ molecule detaches from the chain and produces $\mathrm{N}_{6}+\mathrm{N}_{2}$, while in the second case, both external $\mathrm{N}_{3}$ fragments simultaneously break away from the central nitrogen atoms, resulting in $2 \mathrm{~N}_{3}+\mathrm{N}_{2}$. The scheme in Figure 8 graphically depicts the relative electronic energies of the various conformers calculated in gas phase using the APFD functional. The structures depicted correspond to the EZE isomer only, but are representative for the EEE conformer too. The electronic energy difference between the two

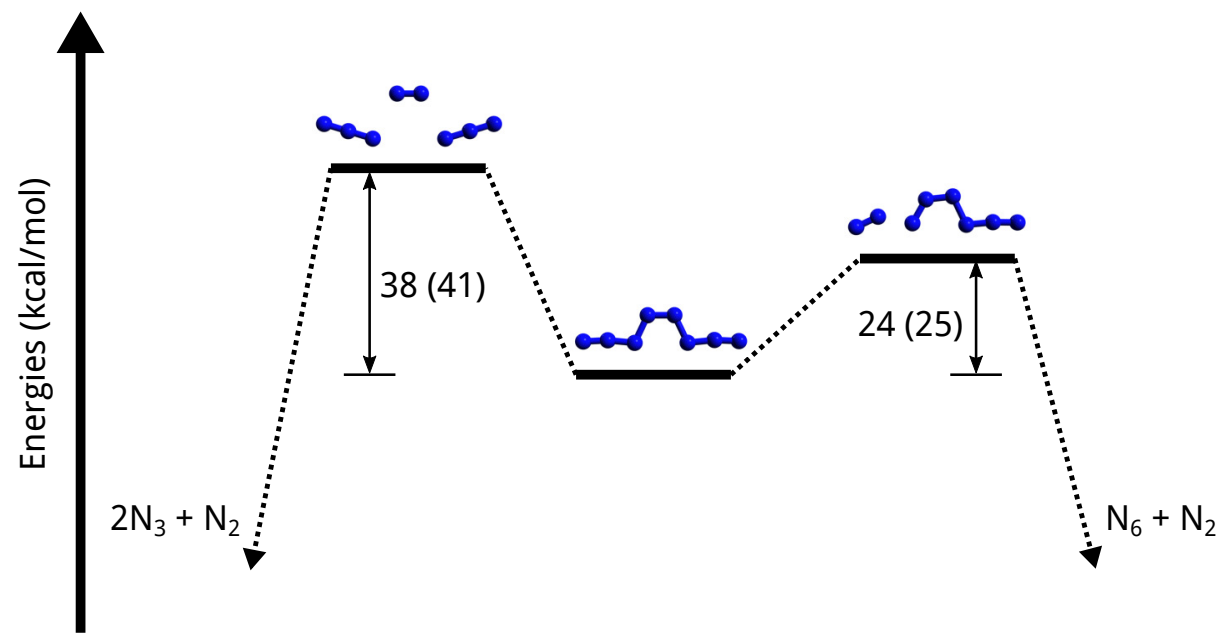

Fig. 8. Potential energy surface of the $\mathrm{N}_{8}$ decomposition pathways in gas phase. Molecules and numbers depicted correspond to the EZE conformer, while the values in parenthesis refer to the EEE conformer.

stable isomers is within $1 \mathrm{kcal} / \mathrm{mol}$ and, as can be seen from Figure 8 , the activation energies for the decomposition reactions are similar for both the EZE and the EEE conformations (numbers in parenthesis). 
Proceeding as in the first part of this contribution, we computed the interaction energies of both isomers confined inside a $(5,5) \mathrm{CNT}$, after a geometry relaxation of the entire system. The computed energies for the EEE and the EZE isomers are $-42.48 \mathrm{kcal} / \mathrm{mol}$ and $-37.34 \mathrm{kcal} / \mathrm{mol}$, respectively, both showing a clear favorable interaction. Subsequent frequency calculations ensured that both structures are true minima of the potential energy surface and thus stable states. A notable effect of the nanotube on $\mathrm{N}_{8}$ can be appreciated by the energy difference of the two isomers when confined in the cavity. From a difference of less than $1 \mathrm{kcal} / \mathrm{mol}$, the EEE conformation is now more stable than the EZE conformation by $5.27 \mathrm{kcal} / \mathrm{mol}$.

For both stable conformations, the transition state structures (Figure 9) of the two known decomposition pathways in gas phase (as illustrated for EZE in Figure 8) were confined inside the carbon nanotube wih the aim to investigate if the gas phase transitions states remain such when confined in the CNT. If that is the case, we are interested in the activation energies to undergo decomposition. Preliminary results suggest that not all the transition states depicted in Fig-
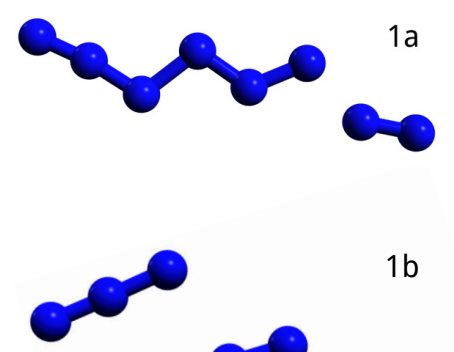

$1 b$

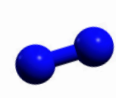

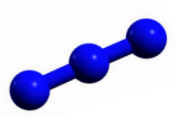

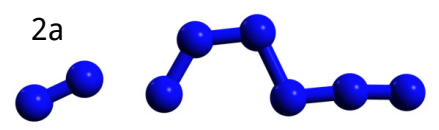

$2 b$

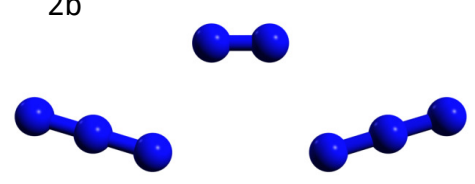

Fig. 9. Transition state structures of the decomposition reactions in gas phase for (1) the EEE conformer and (2) the EZE conformer

ure 9 are still valid inside a $(5,5)$ CNT. Of the four structures shown in Figure 9, only (1a) appears to be a transition state. This is probably due to the more linear conformation (with respect to the other three geometries) which might "fit" better in the cavity, such that the molecule does not undergo a large distortion. Such an interpretation is valid also for the stable isomers, as the EEE conformer, being slightly more "linear" than the EZE one, is favored by approximately 5 $\mathrm{kcal} / \mathrm{mol}$ over the EZE structure. We argue that steric effects are likely to play a crucial role in favoring certain isomers over others, selectively closing certain reaction pathways and possibly giving rise to new stable and metastable structures otherwise not existing in gas phase.

Nonetheless, on the base of these preliminary results only, it is yet not possible to make definitive conclusions, and a full exploration of the potential energy 
surface for the different reactions inside carbon nanotubes still has to be carried out.

\section{Conclusions}

In the present contribution we studied the confinement of the pentanitrogen cation inside carbon nanotubes by means of high level quantum chemical calculations. A combination of wave function methods and density functional theory was used to obtain interaction energies, relaxation effects and allowed for a charge distribution analysis, based on natural bond orbitals. It is shown that, despite favorable unrelaxed interaction energies between $\mathrm{N}_{5}^{+}$and carbon nanotubes, a charge transfer from the host system to the guest cation is responsible for triggering the decomposition of the latter into the azide anion and molecular nitrogen. As previously shown in the literature[10] and confirmed here, a single electron is enough to initiate the barrierless decomposition of the pentanitrogen cation. Such a transfer initially occurs because the electron affinity of $\mathrm{N}_{5}^{+}$is larger than the ionization potential of the carbon nanotube. This process eventually leads to a second charge transfer, in which the intermediate $\mathrm{N}_{3}$ radical gains a second electron from the nanotube, resulting in $\mathrm{N}_{3}^{-}+\mathrm{N}_{2}$.

A possible way to circumvent the decomposition, is the addition of a counterion in the cavity, which might stabilize $\mathrm{N}_{5}^{+}$. To this end, we presented preliminary results of the encapsulation of $\mathrm{N}_{8}$ inside a $(5,5) \mathrm{CNT}$, as a possible result of the reaction $\mathrm{N}_{3}^{-}+\mathrm{N}_{5}^{+} \rightarrow \mathrm{N}_{8}$. We have not yet explicitly considered the reaction, but instead have investigated if the possible $\mathrm{N}_{8}$ product is favorably hosted in the cavity of the carbon nanotube.

Preliminary results show that two linear isomers of $\mathrm{N}_{8}$ stable in gas phase are stable inside the nanotube too, with favorable interaction energy. Moreover, the relative energy difference between the two isomers is slightly increased by few $\mathrm{kcal} / \mathrm{mol}$. The transition states of two decomposition pathways existing in gas phase were considered, suggesting that not all of them remain valid when confined. The results so far obtained for $\mathrm{N}_{8}$ appear to be explicable in terms of geometric effects, where the "more" linear EEE isomer is more stable than the EZE isomer. A similar argument is valid for the transition states too.

Despite being still an ongoing research, these findings suggest that steric effects due to the restricted space available in the cavity can close certain reaction pathways and favor certain isomers over others. The diameter of the nanotube could be used as a tunable parameter providing fine control on the encapsulated molecule. In particular, the aim is to either increase the activation energy or even close the reaction pathways leading to decomposition of $\mathrm{N}_{8}$, thus favoring selected isomers inside the cavity. The final goal of this research is to propose alternative ways to store polynitrogen molecules without recurring to extreme conditions. Still, one has to face the problem of producing the stable PN system in the first place, but also in this case, CNTs can serve the purpose and perform as a nanoreactor. 


\section{Acknowledgments}

The results included in this publication have received funding from the European Union's Horizon 2020 research and innovation programme under the Marie Skłodowska-Curie grant agreement $\mathrm{n}^{\circ} 642294$. S. E. and T. L. acknowledge the "Programme Investissements d'Avenir" ANR-11-IDEX-0002-02, reference ANR10-LABX-0037-NEXT for financial support. N. F.-L. acknowledges Fondazione Cassa di Risparmio di Perugia (P 2014/1255, ACT 2014/6167) for funding. The calculations of this work have been partly performed using the resources of the HPC center CALMIP, under the grant 2016-p1048. S. B. wishes to thank Dr. Oriana Brea for insightful discussions. 


\section{References}

1. Samartzis, P.C., Wodtke, A.M.: All-nitrogen chemistry: how far are we from $\mathrm{N}_{60}$ ? Int. Rev. Phys. Chem. 25(4) (oct 2006) 527-552

2. Zarko, V.E.: Searching for Ways to Create Energetic Materials Based on Polynitrogen Compounds (Review). Combust. Explos. Shock Waves 46(2) (2010) 121-131

3. Curtius, T.: Ueber Stickstoffwasserstoffsäure (Azoimid) $\mathrm{N}_{3} \mathrm{H}$. Berichte der Dtsch. Chem. Gesellschaft 23(2) (1890) 3023-3033

4. Christe, K.O., Wilson, W.W., Sheehy, J.A., Boatz, J.A.: $\mathrm{N}_{5}^{+}$: A Novel Homoleptic Polynitrogen Ion as a High Energy Density Material. Angew. Chemie Int. Ed. 38(13/14) (1999) 2004-2009

5. Wang, X., Hu, H.r., Tian, A., Wong, N., Chien, S.H., Li, W.K.: An isomeric study of $\mathrm{N}_{5}^{+}, \mathrm{N}_{5}$, and $\mathrm{N}_{5}^{-}$: a Gaussian-3 investigation. Chem. Phys. Lett. 329(5-6) (oct 2000) 483-489

6. Gagliardi, L., Orlandi, G., Evangelisti, S., Roos, B.O.: A theoretical study of the nitrogen clusters formed from the ions $\mathrm{N}_{3}^{-}, \mathrm{N}_{5}^{+}$, and $\mathrm{N}_{5}^{-}$. J. Chem. Phys. 114(24) (2001) 10733-10737

7. Fau, S., Bartlett, R.J.: Possible Products of the End-On Addition of $\mathrm{N}_{3}^{-}$to $\mathrm{N}_{5}^{+}$ and Their Stability. J. Phys. Chem. A 105(16) (apr 2001) 4096-4106

8. Evangelisti, S., Leininger, T.: Ionic nitrogen clusters. J. Mol. Struct. THEOCHEM 621(1-2) (2003) 43-50

9. Fau, S., Wilson, K.J., Bartlett, R.J.: On the Stability of $\mathrm{N}_{5}^{+} \mathrm{N}_{5}^{-}$. J. Phys. Chem. A 106(18) (2002) 4639-4644

10. Dixon, D.A., Feller, D., Christe, K.O., Wilson, W.W., Vij, A., Vij, V., Jenkins, H.D.B., Olson, R.M., Gordon, M.S.: Enthalpies of Formation of Gas-Phase $\mathrm{N}_{3}$, $\mathrm{N}_{3}^{-}, \mathrm{N}_{5}^{+}$, and $\mathrm{N}_{5}^{-}$from Ab Initio Molecular Orbital Theory, Stability Predictions for $\mathrm{N}_{5}^{+} \mathrm{N}_{3}^{-}$and $\mathrm{N}_{5}^{+} \mathrm{N}_{5}^{-}$, and Experimental Evidence for the Instability of $\mathrm{N}_{5}^{+} \mathrm{N}_{3}^{-}$. J. Am. Chem. Soc. 126(3) (2004) 834-843

11. Tomasino, D., Kim, M., Smith, J., Yoo, C.S.: Pressure-Induced SymmetryLowering Transition in Dense Nitrogen to Layered Polymeric Nitrogen (LP-N) with Colossal Raman Intensity. Phys. Rev. Lett. 113(20) (nov 2014) 205502

12. Frost, M., Howie, R.T., Dalladay-Simpson, P., Goncharov, A.F., Gregoryanz, E.: Novel high-pressure nitrogen phase formed by compression at low temperature. Phys. Rev. B 93(2) (jan 2016) 024113

13. Eremets, M.I., Gavriliuk, A.G., Trojan, I.A., Dzivenko, D.A., Boehler, R.: Singlebonded cubic form of nitrogen. Nat. Mater. 3(8) (aug 2004) 558-563

14. Hirshberg, B., Gerber, R.B., Krylov, A.I.: Calculations predict a stable molecular crystal of $\mathrm{N}_{8}$. Nat. Chem. 6(1) (2014) 52-56

15. Greschner, M.J., Zhang, M., Majumdar, A., Liu, H., Peng, F., Tse, J.S., Yao, Y.: A New Allotrope of Nitrogen as High-Energy Density Material. J. Phys. Chem. A 120(18) (2016) 2920-2925

16. Steele, B.A., Oleynik, I.I.: Sodium pentazolate: A nitrogen rich high energy density material. Chem. Phys. Lett. 643 (jan 2016) 21-26

17. Adeleke, A.A., Greschner, M.J., Majumdar, A., Wan, B., Liu, H., Li, Z., Gou, H., Yao, Y.: Single-bonded allotrope of nitrogen predicted at high pressure. Phys. Rev. B 96(22) (dec 2017) 224104

18. Bondarchuk, S.V., Minaev, B.F.: Super high-energy density single-bonded trigonal nitrogen allotrope - a chemical twin of the cubic gauche form of nitrogen. Phys. Chem. Chem. Phys. 19(9) (2017) 6698-6706 
19. Steele, B.A., Stavrou, E., Crowhurst, J.C., Zaug, J.M., Prakapenka, V.B., Oleynik, I.I.: High-Pressure Synthesis of a Pentazolate Salt. Chem. Mater. 29(2) (jan 2017) $735-741$

20. Yu, S., Huang, B., Zeng, Q., Oganov, A.R., Zhang, L., Frapper, G.: Emergence of Novel Polynitrogen Molecule-like Species, Covalent Chains, and Layers in Magnesium-Nitrogen $\mathrm{Mg}_{x} \mathrm{~N}_{y}$ Phases under High Pressure. J. Phys. Chem. C 121(21) (jun 2017) 11037-11046

21. Zhang, C., Sun, C., Hu, B., Yu, C., Lu, M.: Synthesis and characterization of the pentazolate anion cyclo- $\mathrm{N}_{5}^{-}$in $\left(\mathrm{N}_{5}\right)_{6}\left(\mathrm{H}_{3} \mathrm{O}\right)_{3}\left(\mathrm{NH}_{4}\right)_{4} \mathrm{Cl}$. Science 355(6323) (jan 2017) 374-376

22. Benchafia, E.M., Yao, Z., Yuan, G., Chou, T., Piao, H., Wang, X., Iqbal, Z.: Cubic gauche polymeric nitrogen under ambient conditions. Nat. Commun. 8(1) (dec 2017) 930

23. Abou-Rachid, H., Hu, A., Timoshevskii, V., Song, Y., Lussier, L.S.: Nanoscale High Energetic Materials: A Polymeric Nitrogen Chain $\mathrm{N}_{8}$ Confined inside a Carbon Nanotube. Phys. Rev. Lett. 100(19) (2008) 196401

24. Ji, W., Timoshevskii, V., Guo, H., Abou-Rachid, H., Lussier, L.: Thermal stability and formation barrier of a high-energetic material $\mathrm{N}_{8}$ polymer nitrogen encapsulated in (5,5) carbon nanotube. Appl. Phys. Lett. 95(2) (2009) 021904

25. Zheng, F., Yang, Y., Zhang, P.: Polymeric Nitrogen Chains Confined in Carbon Nanotube Bundle. Int. J. Mod. Phys. B 26(18) (2012) 1250047

26. Benchafia, E.M., Yu, C., Sosnowski, M., Ravindra, N.M., Iqbal, Z.: Plasma Synthesis of Nitrogen Clusters on Carbon Nanotube Sheets. JOM 66(4) (apr 2014) 608-615

27. Wu, Z., Benchafia, E.M., Iqbal, Z., Wang, X.: N $\mathrm{N}_{8}^{-}$Polynitrogen Stabilized on MultiWall Carbon Nanotubes for Oxygen-Reduction Reactions at Ambient Conditions. Angew. Chemie - Int. Ed. 126 (2014) 12763-12767

28. Timoshevskii, V., Ji, W., Abou-Rachid, H., Lussier, L.S., Guo, H.: Polymeric nitrogen in a graphene matrix: An ab initio study. Phys. Rev. B 80(11) (sep 2009) 115409

29. Sharma, H., Garg, I., Dharamvir, K., Jindal, V.K.: Structure of Polynitrogen Clusters Encapsulated in $\mathrm{C}_{60}$ : A Density Functional Study. J. Phys. Chem. C 114(19) (2010) 9153-9160

30. Zheng, F., Wang, C., Zhang, P.: Polymeric Nitrogen Chain Confined Inside a Silicon Carbide Nanotube. J. Comput. Theor. Nanosci. 9(8) (aug 2012) 1129-1133

31. Liu, S., Yao, M., Ma, F., Liu, B., Yao, Z., Liu, R., Cui, T., Liu, B.: High Energetic Polymeric Nitrogen Stabilized in the Confinement of Boron Nitride Nanotube at Ambient Conditions. J. Phys. Chem. C 120(30) (aug 2016) 16412-16417

32. Faginas-Lago, N., Yeni, D., Huarte, F., Wang, Y., Alcamí, M., Martin, F.: Adsorption of Hydrogen Molecules on Carbon Nanotubes Using Quantum Chemistry and Molecular Dynamics. J. Phys. Chem. A 120(32) (aug 2016) 6451-6458

33. Battaglia, S., Evangelisti, S., Faginas-Lago, N., Leininger, T.: $\mathrm{N}_{3}^{-}$azide anion confined inside finite-size carbon nanotubes. J. Mol. Model. 23(10) (oct 2017) 294

34. Becke, A.D.: Density-functional exchange-energy approximation with correct asymptotic behavior. Phys. Rev. A 38(6) (sep 1988) 3098-3100

35. Becke, A.D.: Density-functional thermochemistry. III. The role of exact exchange. J. Chem. Phys. 98(7) (apr 1993) 5648-5652

36. Lee, C., Yang, W., Parr, R.G.: Development of the Colle-Salvetti correlation-energy formula into a functional of the electron density. Phys. Rev. B 37(2) (jan 1988) $785-789$ 
37. Austin, A., Petersson, G.A., Frisch, M.J., Dobek, F.J., Scalmani, G., Throssell, K.: A Density Functional with Spherical Atom Dispersion Terms. J. Chem. Theory Comput. 8(12) (2012) 4989-5007

38. Hehre, W.J., Ditchfield, R., Stewart, R.F., Pople, J.A.: Self-Consistent MolecularOrbital Methods. I. Use of Gaussian Expansions of Slater-Type Atomic Orbitals. J. Chem. Phys. 51(6) (mar 1969) 2657-2664

39. Boys, S.F., Bernardi, F.: The calculation of small molecular interactions by the differences of separate total energies. Some procedures with reduced errors. Mol. Phys. 19(4) (1970) 553-566

40. Angeli, C., Cimiraglia, R., Evangelisti, S., Leininger, T., Malrieu, J.P.: Introduction of $n$-electron valence states for multireference perturbation theory. J. Chem. Phys. 114(23) (jun 2001) 10252-10264

41. Angeli, C., Cimiraglia, R., Malrieu, J.P.: $n$-electron valence state perturbation theory: A spinless formulation and an efficient implementation of the strongly contracted and of the partially contracted variants. J. Chem. Phys. 117(20) (2002) 9138-9153

42. Angeli, C., Pastore, M., Cimiraglia, R.: New perspectives in multireference perturbation theory: The $n$-electron valence state approach. Theor. Chem. Acc. 117(5-6) (2007) 743-754

43. Roos, B.O., Taylor, P.R., Siegbahn, P.E.M.: A complete active space SCF method (CASSCF) using a density matrix formulated super-CI approach. Chem. Phys. 48(2) (1980) 157-173

44. Werner, H.J., Knowles, P.J., Knizia, G., Manby, F.R., Schütz, M., Celani, P., Győrffy, W., Kats, D., Korona, T., Lindh, R., Mitrushenkov, A.O., Rauhut, G., Shamasundar, K.R., Adler, T.B., Amos, R.D., Bernhardsson, A., Berning, A., Cooper, D.L., Deegan, M.J.O., Dobbyn, A.J., Eckert, F., Goll, E., Hampel, C., Hesselmann, A., Hetzer, G., Hrenar, T., Jansen, G., Köppl, C., Liu, Y., Lloyd, A.W., Mata, R.A., May, A.J., McNicholas, S.J., Meyer, W., Mura, M.E., Nicklass, A., O’Neill, D.P., Palmieri, P., Peng, D., Pflüger, K., Pitzer, R., Reiher, M., Shiozaki, T., Stoll, H., Stone, A.J., Tarroni, R., Thorsteinsson, T., Wang, M.: MOLPRO, version 2015.1, a package of ab initio programs (2015)

45. Werner, H.J., Knowles, P.J., Knizia, G., Manby, F.R., Schütz, M.: Molpro: A general-purpose quantum chemistry program package. Wiley Interdiscip. Rev. Comput. Mol. Sci. 2(2) (2012) 242-253

46. Frisch, M.J., Trucks, G.W., Schlegel, H.B., Scuseria, G.E., Robb, M.A., Cheeseman, J.R., Scalmani, G., Barone, V., Mennucci, B., Petersson, G.A., Nakatsuji, H., Caricato, M., Li, X., Hratchian, H.P., Izmaylov, A.F., Bloino, J., Zheng, G., Sonnenberg, J.L., Hada, M., Ehara, M., Toyota, K., Fukuda, R., Hasegawa, J., Ishida, M., Nakajima, T., Honda, Y., Kitao, O., Nakai, H., Vreven, T., Montgomery Jr., J.A., Peralta, J.E., Ogliaro, F., Bearpark, M., Heyd, J.J., Brothers, E., Kudin, K.N., Staroverov, V.N., Kobayashi, R., Normand, J., Raghavachari, K., Rendell, A., Burant, J.C., Iyengar, S.S., Tomasi, J., Cossi, M., Rega, N., Millam, J.M., Klene, M., Knox, J.E., Cross, J.B., Bakken, V., Adamo, C., Jaramillo, J., Gomperts, R., Stratmann, R.E., Yazyev, O., Austin, A.J., Cammi, R., Pomelli, C., Ochterski, J.W., Martin, R.L., Morokuma, K., Zakrzewski, V.G., Voth, G.A., Salvador, P., Dannenberg, J.J., Dapprich, S., Daniels, A.D., Farkas, Ö., Foresman, J.B., Ortiz, J.V., Cioslowski, J., Fox, D.J.: Gaussian 09 Revision D.01

47. Reed, A.E., Weinstock, R.B., Weinhold, F.: Natural population analysis. J. Chem. Phys. 83(2) (1985) 735-746

48. Glendening, E.D., Badenhoop, J.K., Reed, A.D., Carpenter, J.E., Weinhold, F.: NBO Version 3.1 
49. Hanwell, M.D., Curtis, D.E., Lonie, D.C., Vandermeersch, T., Zurek, E., Hutchison, G.R.: Avogadro: an advanced semantic chemical editor, visualization, and analysis platform. J. Cheminform. 4(1) (2012) 17

50. Grimme, S., Antony, J., Ehrlich, S., Krieg, H.: A consistent and accurate ab initio parametrization of density functional dispersion correction (DFT-D) for the 94 elements H-Pu. J. Chem. Phys. 132(15) (2010)

51. Buonocore, F., Trani, F., Ninno, D., Di Matteo, A., Cantele, G., Iadonisi, G.: Ab initio calculations of electron affinity and ionization potential of carbon nanotubes. Nanotechnology 19(2) (jan 2008) 025711 